Applied Physiology, Nutrition, and Metabolism

Canadian Science Publishing Physiologie appliquée, nutrition et métabolisme

\title{
Nutra-Ergonomics: Influence of nutrition on physical employment standards and the health of workers
}

\begin{tabular}{|r|l|}
\hline Journal: & Applied Physiology, Nutrition, and Metabolism \\
\hline Manuscript ID & apnm-2015-0531.R1 \\
\hline Manuscript Type: & Review \\
\hline Date Submitted by the Author: & 28-Jan-2016 \\
\hline Complete List of Authors: & $\begin{array}{l}\text { Shearer, Jane; University of Calgary, } \\
\text { Graham, Terry; University of Guelph, } \\
\text { Skinner, Tina; The University of Queensland, School of Human Movement } \\
\text { Studies }\end{array}$ \\
\hline Keyword: & $\begin{array}{l}\text { nutrition < nutritionn, ergogenic aids < nutrition, hydration < hydration, } \\
\text { ergonomics, performance }\end{array}$ \\
\hline &
\end{tabular}

SCHOLARONE ${ }^{m}$

Manuscripts 
Best Practice in Physical Employment Standards: An International Perspective. Second International Conference on Physical Employment. Standards (PES 2015). Canmore, AB. CANADA. August $23 \square$ 28,2015

Invited Review

Nutra-Ergonomics: Influence of nutrition on physical employment standards and the health of workers

Jane Shearer $^{1}$, Terry E. Graham ${ }^{2} \&$ Tina L. Skinner ${ }^{3}$

${ }^{1}$ Department of Biochemistry \& Molecular Biology, Cumming School of Medicine. Faculty of Kinesiology, University of Calgary, Calgary, Alberta, CANADA. E: jshearer@ucalgary.ca

${ }^{2}$ Department of Human Health and Nutritional Sciences, University of Guelph, 50 Stone Road East, Guelph, Ontario. CANADA. E: terrygra@uoguelph.ca

${ }^{3}$ Centre for Research on Exercise, Physical Activity and Health, School of Human Movement and Nutrition Sciences, Faculty of Health and Behavioural Sciences, The University of Queensland, Brisbane, Queensland, AUSTRALIA. E: t.skinner@uq.edu.au

Corresponding Author:

Jane Shearer. Address: Faculty of Kinesiology, University of Calgary, Calgary, Alberta, CANADA Phone: 403.220.3431,Fax: 403.284.3553,Email: jshearer@ucalgary.ca 


\begin{abstract}
The importance of ergonomics across several scientific domains including biomechanics, psychology, sociology and physiology have been extensively explored. However, the role of other factors that may influence the health and productivity of workers, such as nutrition, is generally overlooked. Nutraergonomics describes the interface between workers, their work environment and performance in relation to their nutritional status. It considers nutrition to be an integral part of a safe and productive workplace that encompasses physical and mental health as well as the long-term wellbeing of workers. This review explores the knowledge, awareness and common practises of nutrition, hydration, stimulants and fortified product use employed prior to physical employment standards testing and within the workplace. The influence of these nutra-ergonomic strategies on physical employment standards, worker safety and performance will be examined. Further, the roles, responsibilities and implications for the applicant, worker and the employer will be discussed within the context of nutra-ergonomics, with reference to the provision and sustainability of an environment conducive to optimise worker health and wellbeing. Beyond physical employment standards, workplace productivity and performance, the influence of extended or chronic desynchronisation (irregular or shift work) in the work schedule on metabolism and long-term health, including risk of developing chronic and complex diseases, is discussed. Finally, practical nutra-ergonomic strategies and recommendations for the applicant, worker and employer alike will be provided to enhance the short- and long-term safety, performance, health and wellbeing of workers.
\end{abstract}

\title{
234 words (250 word limit)
}

Keywords: Nutrition, Nutra-Ergonomics, Ergonomics, Performance, Health, Chronic Disease, Physical Employment Standards 


\section{Introduction}

Ergonomics has many definitions but for the purpose of this review it is described as the study of the interface between the worker and the environment with the intention to design the work task to enhance the safety and health of the worker and potentially increase efficiency. Ergonomics often includes biomechanics, psychology, sociology, physiology and a number of other sciences. Common aims of the discipline include making the workplace safer, making the work task easier and optimising the physical and mental health of the workers. Results of ergonomic investigations are clearly focused on the worker, but have direct implications for the responsibilities of the employer, such as recommendations for work team size, worker physical characteristics, duration of the work task, and/or modifications of work space/task to enhance diversity of workers within the workforce. Whilst the nutritional status of the worker has the potential to influence many work tasks and thus the results of ergonomics assessment, very rarely is nutrition considered in these investigations. This is in stark contrast to the field of sports science where nutritional strategies to optimise performance have been extensively investigated and best practise evidence-based recommendations and position stands developed (Campbell et al. 2007; Campbell et al. 2013; Goldstein et al. 2010). Athletes are not unlike workers who need to safely and optimally complete physically and/or mentally challenging tasks and adequately recover to return to work the next day. Indeed, the physical and mental preparation required prior to a sporting event is very similar to the preparation required by applicants prior to physical employment standards testing. Therefore, the term nutra-ergonomics is introduced within this review with the aim of emphasizing the importance of this field of knowledge on work task safety and performance, and the immediate and future health of the worker. How the work task and conditions can alter the nutritional needs of the worker will also be explored.

Several provocative questions warrant consideration when exploring this field of research. Firstly, should the employer provide the worker with accurate nutritional knowledge to make the work 
task easier or safer or to make the worker more efficient? Further, is it the employer's responsibility to provide quality nutrition advice? With the food industry constantly marketing products with remarkable claims regarding health, alertness, energy, fatigue-reduction, etc., the worker may be making poor nutritional decisions due to a lack of accurate information regarding perceived performance benefits of certain products. Therefore, provision of sound nutritional advice may not only enhance workplace safety and efficiency, it may also improve the health and reduce the chronic disease risk of the worker. Secondly, is it the responsibility of the employer to make nutritious foods available within the workplace or conversely not to make unhealthy choices available? It would be scandalous in most occupations if an employer did not provide clean drinking water, appropriate meal breaks, accurate occupational health and safety advice and procedures, or discourage the consumption of alcohol during work, as failure to make these provisions would reduce productivity and worker safety. However, no similar concern is raised if an employer provides food dispensing machines or a cafeteria with unhealthy products, although the act of making such products easily available could be seen as encouraging their consumption. Furthermore there is the potential that poor nutritional choices may reduce productivity, alertness, and subsequent worker health and safety.

Therefore, the aims of this review are to introduce the concept of nutra-ergonomics, review the evidence pertaining to the interface between all workers (including active, inactive and shift workers), their work environment and performance in relation to their nutritional status, and make recommendations to both the employer and worker for optimal health and performance.

\section{Hydration in the workplace: influence on performance and wellbeing}

The human body is comprised of $\sim 50-70 \%$ water, with total water content requiring tight regulation to maintain optimal function (Maughan 2003). During daily living the body loses fluid via urine $(\sim 1400 \mathrm{ml})$, feces $(\sim 200 \mathrm{ml})$, respiration $(\sim 400 \mathrm{ml})$ and skin $(\sim 500 \mathrm{ml})$ (Maughan 2003$)$, however 
these amounts are highly individual and dependant on various factors (Sawka et al. 2007). When working in physically-demanding professions and/or hot, humid conditions, more fluid is lost through sweating leading to potential dehydration if it is not replaced. Dehydration, best indicated as a rapid loss of body mass, is known to have several negative effects on physical, psychological and cognitive performance. During dehydration there is active movement from intracellular to extracellular fluid, with a reduction in plasma volume despite an increase in heart rate, placing greater strain on the cardiovascular system to maintain normal blood supply to the muscles, brain and organs (GonzalezAlonso et al. 1998). These changes become more severe as dehydration progresses.

The importance of maintaining hydration in the workplace is not a new concept; a substantial body of evidence highlights the importance of hydration in facilitating optimal performance. However, we commonly associate this as only a problem in physically demanding situations and harsh environments. It is well evidenced that there is a difference in physiological stress between euhydrated and dehydrated individuals, with several reviews indicating minimal dehydration (as low as 1-2\% body mass loss) potentially affecting mood, attention, reaction time, vigilance, working memory and increased tension/anxiety (American Dietetic Association. 2009; Ganio et al. 2011; Masento et al. 2014; Maughan 2003; Maughan et al. 2007). Moderate dehydration ( $2 \%$ body mass loss) has commonly been associated with detrimental physiological effects and reductions in endurance exercise performance, particularly in hot conditions (Burge et al. 1993; Ebert et al. 2007; Lopez et al. 2011; Maughan et al. 1996; McConell et al. 1997; Sawka et al. 2007). Therefore, hydration needs to be considered across a spectrum of professions. For example, a cross sectional study of 88 Australian miners found $58 \%$ experienced dehydration (defined as a urine specific gravity $>1.020$ ) both before and after their shift, with three workers pre-shift and four workers post-shift displaying clinical dehydration (urine specific gravity >1.030) (Polkinghorne et al. 2013). Even higher proportions of dehydration $(>80 \%)$ were reported in 15 surface mine blast crew workers before and throughout their shift (Hunt et 
al. 2014). Recent work by Alomar et al. (2013) examined hydration in emergency room personnel following a shift. Results showed that emergency room physicians lost on average $0.6 \mathrm{~kg}$ over the course of a typical $8 \mathrm{~h}$ shift. While this level of dehydration would be expected to have a minimal impact on 'performance', it demonstrates the potential for varying levels of dehydration to be observed in professions where the importance of maintaining hydration may not have previously been considered.

Whilst the aforementioned studies and reviews suggest minimal dehydration may affect a range of important aspects of worker productivity across several professions, results from studies presented had varying methodologies and other confounding factors that may have contributed to cognitive decrement, such as the addition of heat and performance intensity. Indeed, there is evidence to suggest that cognitive function may be preserved during water deprivation up to $2.6 \%$ body mass loss under the premise that dehydrated participants are able to increase their efforts to achieve the desired task (Szinnai et al. 2005). Further, habituation to dehydration may also attenuate performance decrements, likely via reducing perceived exertion (Fleming and James 2014). Regardless of these ongoing debates within the dehydration literature, it is well accepted that maintaining hydration is important to the health and performance of many workers, particularly those with high physical demands and/or those who may work in hot, humid conditions.

Generally speaking, worker knowledge of hydration is fairly high with most reporting awareness surrounding the signs, symptoms and consequences of dehydration. Unfortunately, this does not always translate into practice with many knowledgeable workers still suffering from dehydration on a regular basis (Alomar et al. 2013; Mentes 2006). This is especially true among elderly workers whose thirst response, the primary means by which the body signals fluid needs becomes blunted with age. When young individuals (aged 20-28 years) were compared to older individuals (aged 51-60 years) during a 10 day hiking excursion, older individuals became progressively more dehydrated compared to their 
younger counterparts (Ainslie et al. 2002). In addition, it may take older workers longer to recover from dehydration compared to younger individuals with both serum sodium and osmolality taking longer to return to normal levels following dehydration (Miescher and Fortney 1989). Given this, and the increasing age of the workforce, hydration is still perhaps the most acute nutritional consideration in the workplace.

Beyond visual cues (e.g. pale skin, lack of sweating, lethargy) in the workplace, there are no easy or accurate methods to quickly assess a worker's hydration status. Although urine color may be a superficial indicator, it is not feasible or hygienic in many workplace environments. Employer recommendations for ensuring adequate hydration include keeping records of productivity and accidents in relation to temperature fluctuations as risk and dehydration would be expected to increase with high temperatures and physical exertion. Increasing fluid availability, allowing drink breaks and implementing fluid consumption guidelines are proven strategies to limit dehydration in workers.

\section{Stimulants in the workplace: influence on performance and wellbeing}

This review considers legal stimulants in the workplace, namely caffeine.

\section{Caffeine}

In many regions of the world, coffee is synonymous with the workplace. While coffee contains thousands of biologically-active compounds, the main active ingredient is caffeine. Two-thirds of Canadian adults consume coffee ( $100-140 \mathrm{mg}$ caffeine per cup) on a daily basis (Coffee Association of Canada 2013). While the social aspect of drinking coffee is fundamental to its appeal, its stimulant properties are also attractive to both workers and employers alike.

Although coffee remains the stimulant of choice for most working individuals, there has been a boom in caffeine-containing foods and beverages outside of traditional sources (i.e. coffee, tea, cola drinks, chocolate and cocoa). Of note, caffeine-containing 'energy' drinks (typically marketed as 
'shots' or larger, often sugar-sweetened formulations containing 25-250 mg of caffeine per serving) have recently emerged as a popular and growing market, especially among young adult workers. Sales of caffeine-containing energy drinks have grown exponentially over the past 10 years, with North American sales projected to reach \$21 billion by 2017 (ReportsnReports 2013; The Economist 2013). Generally young adult men consume more sugar sweetened caffeine-containing energy drinks than women and as do those employed in construction, military, utilities, mining and agriculture (Berger et al. 2011; Miller 2008). Likewise, workers in jobs involving long commutes, long or tedious demands including overtime, high physical demands, low remuneration as well as those working in multiple jobs are more likely to consume energy drinks (Grandner et al. 2014; Pichainarong et al. 2004; Stephens et al. 2014). In these scenarios caffeine is typically used to offset the effects of insufficient rest and sleep.

From a performance perspective caffeine is a psychoactive drug that improves simple cognitive skills, vigilance, attention, reaction time, perception of effort, memory, and mood. The weight of research evidence suggests the cognitive (e.g. vigilance, attention, psychomotor performance) benefits of caffeine are heightened during sleep deprivation, which may be of particular importance to shift workers and occupations for which major consequences may result from poor vigilance e.g. military. The weight of research evidence suggests that the ingestion of 3-6 mg/kg body mass of caffeine (i.e. 200-400 mg for the average adult (Walpole et al. 2012) elicits significant improvements in endurance (>30 min) performance (Doherty 1998; Graham and Spriet 1991; Graham and Spriet 1995; Graham et al. 1998; Spriet and Gibala 2004; Spriet et al. 1992). Small doses of 1-2 mg/kg body mass caffeine (i.e. 50-200 mg for the average adult (Walpole et al. 2012) can improve reaction time, alertness, and visual information processing (Haskell et al. 2005), which are crucial to performance in many professions. Thus many workers may well consume more caffeine than is necessary for beneficial effects, and if consuming caffeine in extremely high doses, may actually be at risk of reducing their performance. 
Evidence of potential side effects of caffeine at doses $\geq 500 \mathrm{mg}$, such as gastrointestinal distress, dizziness, anxiety, irritability and an inability to focus, have been reported (Bruce et al. 1986; Hasenfratz and Battig 1994). A very high intake of caffeine may impair reaction time and alertness, and negate any stimulatory effect of caffeine on performance (Hespel et al. 2006). In addition, a meta-analysis of the impact of coffee and caffeine on blood pressure indicated that the consumption of $>410 \mathrm{mg} /$ day caffeine produced significantly greater elevations in systolic blood pressure when compared to lower caffeine doses (Noordzij et al. 2005). Thus, the 'optimal' dose of caffeine may depend upon the demands of the profession, or more specifically, the type of work being performed. For workers who rely on reaction time and alertness such as skilled labour division jobs, a low dose (1$2 \mathrm{mg} / \mathrm{kg}$ ) of caffeine may be preferable to a larger dose. On the other hand workers seeking to enhance physical performance for physical employment standards or over an extended duration (e.g. military, firefighters), and for whom mental over-arousal will not potentially cause problems, a dose in the range of 3-6 mg/kg may be more appropriate (Hespel et al. 2006).

Compared to the misuse of prescription and illicit drugs that can cause several side effects, abuse, addiction, and induction of psychiatric disorders, caffeine is a legal alternative for pharmacological cognitive enhancement. However, side effects of caffeine consumption, including reduced sleep quality (increased time taken to fall asleep, increased number of awakenings, reduced overall sleep time) (Lloret-Linares et al. 2012) and insulin resistance (Beaudoin et al. 2013; Shearer and Graham 2014) following acute caffeine intake, transient headaches, drowsiness, and fatigue (Smith 2002) following caffeine cessation, and anxiety in susceptible individuals following higher doses, must be considered by workers before deciding whether to consume caffeinated products to try to enhance their work performance.

The hot temperature and bitter taste of coffee and tea make excessive caffeine consumption less likely, whilst the plant-based bioactive compounds contained within these beverages, such as 
antioxidants have been shown to be beneficial for health (Ludwig et al. 2014; Preedy 2015). This is in contrast to caffeine-containing energy drinks which are often rapidly consumed due to their sugar content, temperature and concentrated formulations, thereby facilitating the consumption of higher caffeine doses. Further, caffeine-containing energy drinks are often confused with sports drinks marketed to replace fluids and electrolytes lost during physical activities in hot, humid environments. Of note, there is growing evidence from increasing emergency room visits and poison control center calls that caffeine-containing energy drinks likely pose a greater hazard to workers than coffee (Jackson et al. 2013). If caffeine is to be consumed, traditional sources such as coffee and tea are preferable and better for worker's health over sugar sweetened energy drinks in the workplace.

\section{Fortified and performance enhancing food and beverages in the workplace: influence on performance and wellbeing}

A relatively new trend in the food industry is the introduction of 'nutrient' enhanced or fortified products and beverages including vitamin waters, functional fruit and vegetable juices, fruit 'snacks' and sports drinks. These products add amino acids, stimulants, vitamins, minerals and other 'specialty' ingredients (e.g. herbal ingredients) that are marketed to improve attention and physical performance.

In the workplace, the use of such 'performance enhancers' are popular at worksites involving physical labour or shift work. Added nutrients or 'discretionary fortification' are not part of a planned public health intervention (to address a deficiency), but are rather added at the discretion of manufacturers for marketing purposes (Shearer and Elliott 2015). Such products are laden with health claims, yet there is often little evidence to support them. Detailed content analysis of these novel beverages in Canada by Dachner and colleagues (Dachner 2015) show they contain, on average, 4.5 different nutritional fortifications with vitamins B6, B12, B3 (niacin) and C most prevalent. These were, in many cases, in excess or in gross excess of the daily requirement for one if not all added 
nutrients. In the workplace, these beverages are often perceived as time savers or a 'healthy' substitution for a balanced diet.

Many products also market fruit and vegetable claims on their packaging such as 'contains two servings of vegetables' or ' $50 \%$ real fruit'. However, as this marketing relates to ingredients rather than nutrients, there are challenges regarding regulation under food standards codes. Products carrying these claims are absorbed quicker than real fruit resulting in rapid blood glucose spikes (i.e. higher release of insulin, with subsequent suppression of fat oxidation and increased glycogen utilization, or possibly hypoglycemia from rapid muscle uptake of glucose), and are often higher in sodium, saturated fat and sugar, and lower in fiber than fresh fruit and/or vegetables (Wellard et al. 2014). Therefore, consuming these products as a way of meeting fruit and vegetable intake may adversely impact workers diets and subsequent health and wellbeing.

\section{Protein and Amino Acids}

Protein is an essential nutrient in the diet of workers to curb hunger and enhance repair and recovery following physically-demanding work. Almost all adults in the western world achieve adequate protein intake (e.g. nitrogen balance or a range associated with a reduced risk of chronic disease while providing adequate amounts of essential nutrients) through their diet, typically via consumption of a variety of sources including meat, dairy, fish, soy, eggs, lentils, nuts and legumes

(Waern et al. 2015; Wu 2016). In Canada the recommended Dietary Reference Intake for protein is 0.8 $\mathrm{g} / \mathrm{kg}$ body weight $(\mathrm{BW}) /$ day for healthy adults, or 10-30\% of total energy intake with minimal levels of physical activity. This requirement increases when there are physical demands to $1.0,1.3$, and $1.6 \mathrm{~g}$ protein per kg BW per day for individuals with minimal, moderate, and intense physical activity, respectively (Health Canada 2010; Wu 2016). 
Whilst workers with more physically-demanding occupations have slightly greater needs for protein intake, individual amino acid supplementation (rather than whole protein sources) are not needed or beneficial for the majority of the working population. Given this, any advantage of ingesting individual amino acids would only apply to extreme situations of deficiency, stress or disease. In spite of this, individual amino acids have received considerable attention as dietary supplements. Since all proteins are a mixture of amino acids, one can only enhance a single amino acid through supplementation. There are now novel beverages marketed that contain specific amino acids, usually phenylalanine and tyrosine or taurine. Unfortunately while research on these amino acids has been used to justify many marketing claims, the work remains in its infancy and the majority of data examines individual components rather than beverage mixtures (Shearer 2014). The below section provides a brief overview of information on selected amino acids and their potential role in nutra-ergonomics.

\section{Phenylalanine and Tyrosine}

Phenylalanine is an essential amino acid present in dietary protein, as well as in the artificial sweetener aspartame. In addition to supporting the increased rates of protein synthesis when ingested with the other essential amino acids (Borsheim et al. 2002), phenylalanine can be converted by the liver to tyrosine. Tyrosine is a precursor for the neurotransmitters dopamine and norepinephrine, two critical neurotransmitters that regulate mood and behaviour. Acute tyrosine ingestion has been suggested to counter the reductions in cognitive, psychomotor, and mood impairments and symptom intensity in humans induced by very stressful situations, such as demanding environmental conditions (e.g. cold or hypoxia) (Banderet and Lieberman 1989; Mahoney et al. 2007), or prolonged wakefulness (Neri et al. 1995). While the theory is sound, it is important to keep in mind that behaviours such as cognition are extremely complex with many biological inputs. Thomas and coworkers (1999) reported that consuming a large dose of tyrosine $(150 \mathrm{mg} / \mathrm{kg})$ prior to a complex multitasking test, resulted in 
enhanced accuracy and working memory. Shurtleff and colleagues (1994) provided the same dose of tyrosine to participants prior to cold air $\left(4^{\circ} \mathrm{C}\right)$ exposure; the supplement was associated with improved performance in memory tasks. Military cadets who ingested $2 \mathrm{~g}$ of tyrosine a day for six days of a combat training course had enhanced memory and tracking tasks and reduced systolic blood pressure (Deijen et al. 1999). However, the effect of tyrosine in the heat has produced mixed results, with some (Tumilty et al. 2011) but not all (Tumilty et al. 2014; Watson et al. 2012) studies suggesting tyrosine availability may influence fatigue processes under hot conditions. Thus in very challenging physical employment standards or prolonged work environments tyrosine supplementation may have applications, however there is no current evidence to suggest that tyrosine supplementation is beneficial under less extreme work conditions.

\section{Taurine}

Taurine, a popular ingredient in novel drinks, is a nonessential, sulphur-containing amino acid that is often described as a metabolic product of other amino acids. Initially recognized to be an important element in bile and the conjugation of bile salts, taurine is also found in high concentrations in the muscle, heart, central nervous system and other tissues where it has been suggested to play roles in excitation-contraction mechanisms and in fluid balance (Eby and Halcomb 2006). While it is readily absorbed following ingestion, only small amounts enter the tissues. Consumption of taurine in the omnivorous, North American diet typically ranges from 40-400 mg (Schaffer 2014). Expected exposure from energy drinks is $\sim 270 \mathrm{mg}$ per day in regular consumers, and between 1400 and $2300 \mathrm{mg}$ per day in heavy consumers (Schaffer 2014). These levels are low compared to administration of 1000 $\mathrm{mg} / \mathrm{kg}$ body mass per day which has shown no adverse health effects in children or adults (European Food Safety Authority. 2009). Of interest to the present review, taurine may also have weak diuretic and natriuretic effects (Mozaffari et al. 2006), and may stimulate bone loss with excessive consumption 
of sulphur-containing amino acids (Zwart et al. 2005), however, the body of evidence for a beneficial impact is modest at best. Further, many previous investigations supporting a beneficial effect have used doses of taurine that far exceed that which could be achieved through the diet.

\section{Fatty Acids}

After adipose tissue, the brain contains the second highest amount of lipids within the body, with $30-60 \%$ of neural tissue lipid-based (Bauer et al. 2014). Omega-3 polyunsaturated fatty acids are one of the major components of the lipid bilayer of cell membranes in the brain, including docosahexaenoic (DHA), arachidonic (AA) and, in minor part (approximately 1\%), eicosapentaenoic acid (EPA) (Sinclair et al. 2007; Tassoni et al. 2008). In animal models, an inadequate supply of dietary omega-3 polyunsaturated fatty acids can result in a 50-80\% decline in brain DHA and is associated with impaired learning and memory (Moriguchi and Salem 2003). Equivalently low levels of omega-3 polyunsaturated fatty acids are rare in humans, however several studies have explored whether cognitive function and mood, which are central to the performance of many workers, may benefit from supplementation.

Omega-3 fatty acid supplementations containing EPA and DHA in varying amounts have been reported to improve visual attention and information processing speed in some (Fontani et al. 2009; Fontani et al. 2005), but not all (Antypa et al. 2009; Jackson et al. 2012) studies. De Groot et al. (2007) found higher levels of AA were associated with a faster learning curve on the Stroop task measuring general speed of information processing, however the opposite was found with DHA. In contrast, Hamazaki and others (1996) reported that 3 months of $1 \cdot 5-1 \cdot 8 \mathrm{~g} / \mathrm{d}$ DHA (from fish oil) in forty-one healthy students prevented increases in aggression towards others during times of mental stress, but performance on the Stroop was not improved. 
The World Health Organization (WHO) recommends healthy adults regularly consume fish (12 servings per week), providing an equivalent of 200-500 mg of EPA and DHA, and that vegetarians ensure adequate intake of plant sources of alpha-linolenic acid (ALA; e.g. via consumption of walnuts, edible seeds, flaxseed oil) (World Health Organization). Given the contradicting evidence provided by the studies listed above, further research is required before a recommendation regarding supplementation with omega-3 polyunsaturated fatty acids, above and beyond that recommended by the WHO, can be made to workers seeking to enhance their cognitive performance and/or mood.

\section{Extended Work Schedules, Irregular Work and Shiftwork: Impact on Nutrition, Long-Term Health and Wellbeing}

In today's working environment, it is estimated that one in every three employees work outside traditional working hours. These alternate schedules encompass evening work, overtime, shift work, on-call responsibilities, rotating, split or irregular shifts as part of employment. This also includes performing additional work beyond regular working hours. Further, in urban settings long transportation commutes are common. The capacity for working outside traditional work environments has increased dramatically with advances in various technologies including tablets and smart phones. These advances have facilitated global communications and for many the entire world is now the work environment. While these alternate work arrangements are often necessary and may facilitate productivity, it is important to recognize that alternative scheduling can have an impact on our health and wellbeing. For example, prolonged or evening work would be expected to increase sedentary screen-time or sitting. Sitting is now recognized as an independent risk factor associated with elevated risk of all-cause mortality, cardiovascular disease incidence or mortality, cancer incidence or mortality (breast, colon, colorectal, endometrial, and epithelial ovarian), and type 2 diabetes in adults (Biswas et al. 2015). 
In the context of nutra-ergonomics, there is growing interest on the impact of chronic desynchronisation (irregular or shift work) due to its recent association with weight maintenance, obesity and the development of chronic disease states (Antunes et al. 2010; Wang et al. 2011). Our physiology is closely tied to our circadian rhythms - the physical, mental and behavioral changes that follow a roughly 24-hour, light-dark cycle. This cycle organizes whole body energy homeostasis including energy intake, fat accumulation, caloric expenditure and even regulates the gut microbiota living within our intestines (Leone et al. 2015). Insufficient, short or disturbed sleep - as happens with shift work - alter the body's hunger and satiety signals that result in variation in the timing and amount of food consumed. Long term, this chronic dysynchronization likely contributes to endocrine and metabolic dysregulation that can manifest in terms of weight gain, obesity, insulin resistance, hypertension and lipid profile disturbances (Antunes et al. 2010).

A review by Lowden et al. (2010) examined over 20 studies investigating the dietary habits of shift workers from the 1960s onwards. Data included i) food and meal composition; ii) the timing and frequency of eating; and iii) the average intake of energy and essential non-energy yielding nutrients. Results showed that total energy intake (kcal) on a daily or even weekly basis during shift work was not significantly different to controls or between shifts, but rather the temporal distribution of food consumption as well as the type of food eaten differed. Intake of dietary fiber, especially from fresh fruits and vegetables and minerals including zinc, and vitamins D and E tended to be reduced with shift work (Knutson et al. 1990; Linseisen and Wolfram 1994). Of particular importance, low fiber foods have been linked to food overconsumption and obesity while those high in fiber (pulses-legumes, whole wheat products, etc.) are effective in weight maintenance via satiety-based signaling (Parnell and Reimer 2012). Although caloric density remains unchanged with shift work, workers tend to compromise variety; eat on a schedule (e.g. breaks) rather than due to hunger; replace mixed meals with single food items (e.g. large bag of potato chips); consume easily prepared or instant meals often 
characterized by high caloric density, high sodium content and low nutritive value (e.g. noodle cups); and increase their consumption of sugar-sweetened beverages (Lowden et al. 2010; Tada et al. 2014). Over a long period of time (years to decades), these alterations would certainly be expected to contribute to a less favorable health profile and increased risk of obesity in shift workers. For these reasons, employers need to ensure healthy foods are available to employees, especially when shift or atypical work schedules are involved.

Beyond providing nutrients, it is well documented that sensory, physiological and psychological mechanisms underlie emotional influences on food choice (Gibson 2006). Likewise, food and the state of eating can also elicit profound effects on arousal, mood, alertness and even irritability. For example, having a small amount of food due to lack of a scheduled work break may negatively affect mood and motivation, and therefore impact productivity. Lack of availability of preferred foods, family or social interaction during eating or simply not eating when hungry (e.g. during a night shift) could also have similar effects. In other words, the type, timing and ingestion of nutrients also impact presenteeism, i.e. the measurable extent to which physical or psychosocial symptoms, conditions and diseases affect productivity (Chapman 2005). This is important as more work performance is lost from presenteeism than from absenteeism (Goetzel et al. 2004; Stewart et al. 2003). These data highlight the impact of employee wellbeing and raise questions regarding how to reduce presenteeism and promote productivity in the workplace. As it relates to nutra-ergonomics, well-targeted and efficiently implemented diet-related workplace health promotion interventions have been suggested to improve worker productivity by $1-2 \%$ (Jensen 2011). These productivity gains are likely to more than offset the costs of implementing such interventions in larger workplaces (Jensen 2011). Such interventions would also provide long-term health benefits to the workers.

Another strategy to encourage healthy workplace eating is price manipulation. Price reduction strategies aimed at discounting healthier foods have been examined in the workplace with positive 
results. In general, price reduction strategies have resulted in increased consumption of healthier foods including greater fruit and vegetable consumption (Ball et al. 2015; Waterlander et al. 2013). Reduced prices on lower fat at point-of-purchase sales at vending machines were evaluated in 12 work sites; results demonstrated that price reductions of $10 \%, 25 \%$ and $50 \%$ on lower fat snacks resulted in an increase in sales of $9 \%, 39 \%$ and $93 \%$ compared to usual price conditions, respectively (French 2003). Other studies reported discounts in the range of $\sim 20 \%$ were effective in this regard (Ball et al. 2015). Given these results, improving intake of healthful foods through policy initiatives, vendor collaborations and workplace health initiatives are encouraged.

Obesity \& Chronic Disease Risk of Non-Traditional Work Schedules

Obesity, characterized by excessive body adiposity has reached epidemic proportions (Janssen 2013). In Canada, $33.6 \%$ of adults are overweight, while another $18.5 \%$ are classified as obese [body mass index $($ BMI $)>30 \mathrm{~kg} / \mathrm{m}^{2}$ ] (Public Health Agency of Canada 2011; Twells et al. 2014). By 2019, it is predicted that adults who are overweight or obese will outnumber those of normal weight in half of our provinces in Canada (Twells et al. 2014). The health risks of obesity are well known and include cardiovascular disease, hypertension, cancer and type 2 diabetes (Dietz 1998a; Dietz 1998b; Must and Strauss 1999; Must and Lipman 1999; Reeder et al. 1997), to name but a few. The cause of the increased prevalence of obesity is multifactorial, with declines in physical activity and poor dietary habits playing central roles (Harnack et al. 1999; Tremblay and Willms 2003). Although the causal linkages are unclear, there is growing evidence that job-related factors, including irregular or shiftwork may contribute (Wang et al. 2011). In addition, most workplaces have moved to make tasks less physically demanding (e.g. automation), whilst the portability and availability of high energy dense 'snack food' has increased in the workplace. 
The foods that are made available in the work place and the nutritional knowledge of the worker can both have important implications on the worker's health and productivity. On a daily and even weekly basis, humans are generally excellent at maintaining body mass within a tight range subject to physiological control (Hill et al. 2012). Physiologically, when energy expenditure increases due to work-related activities, there is a compensatory rise in caloric intake to match. Even a very small mismatch in energy balance can have a dramatic impact over years or decades (Hill et al. 2012). Differences in body mass, equivalent to an increase of $\sim 1 \mathrm{BMI}$ unit is thought to be attributable to a combination of factors including poorer food choices, inferior diet quality, fragmented eating as well as reduced levels of leisure time activity (Atkinson and Davenne 2007; Kim et al. 2013).

In considering the metabolic impacts of non-traditional work schedules, there is an abundance of data showing rates of overweight and obesity and some metabolic diseases to be elevated in shift workers (Knutson and Van Cauter 2008; Parkes 2002). Comparison of Italian day and shift workers in the same job revealed small yet significant gains in BMI with shift work (Barbadoro et al. 2013). Similar results have been documented around the globe. In female Korean nurses, there was no relationship between current shift work status and BMI, however, when subjects were segregated by duration of shift work, those working in shift work for longer durations were most likely to be overweight after adjustment of potential cofounders (Kim et al. 2013). This result has also been replicated in Australia where shift work was found to be associated with higher risk of being overweight/obese (Zhao et al. 2011). In Argentina, male factory workers on shift schedules not only had an increase in BMI, but were also at elevated risk for the metabolic syndrome (Sookoian et al. 2007). Likewise, in Brazil, shift work contributed not only to increased body mass, but also a greater accumulation of abdominal adipose tissue, well-known to be related to increased metabolic risk. Shift work may also trigger low grade inflammation as shown by: elevated leukocyte counts (Sookoian et al. 2007); circulating levels of resistin (Burgueno et al. 2010), an endocrine hormone involved in the 
development and progression of insulin resistance; LDL cholesterol (Ulhoa et al. 2011) and the stress hormone cortisol (Manenschijn et al. 2011). The nature and extent of the relationship between shiftwork and obesity is complex and may differ depending on age, family history, socioeconomic status, time of exposure, ethnicity and the type of work being performed (Barbadoro et al. 2013).

Examination of rotating shift working nurses also show they consumed more sugar-sweetened beverages and snacked more frequently compared to their daytime counterparts (Tada et al. 2014). Shift workers are also more likely to smoke, a factor that likely contributes to ill health (Biggi et al. 2008). This is of relevance to the employer as obesity and its associated comorbidities is related to increased rates of long-term sick leave (>7 days) (van Duijvenbode et al. 2009), injury and disability . Other disease states that are increased in shift workers are known to include breast cancer, gastric ulcers and cardiovascular disease, among others (Cornelissen et al. 2008; Knutsson and Boggild 2000; Konturek et al. 2011).

As such, the promotion and implementation of programs aimed at maintaining employee body mass in healthy weight ranges should be a priority. Combined nutrition and/or physical activity education programs in the workplace are recommended (Ni Mhurchu et al. 2010). A systematic analysis evaluating the effectiveness of 24 randomized controlled trials found workplace nutrition and exercise programs resulted in small but significant decreases in body mass of $-1.2 \mathrm{~kg}$ and a reduction in BMI of $-0.47 \mathrm{~kg} / \mathrm{m}^{2}$ (Anderson et al. 2009) compared to control groups. While these losses may seem minimal, it is important to recognize that most individuals between 18 and 49 years gain an average of 0.5-1 kg per year that contributes to weight gain and obesity over time. It is this gradual weight gain that contributes to the obesity epidemic. Cost-effectiveness was analyzed in a subset of these programs, with an estimated employer cost of $\$ 1.50$ to $\$ 4.50 \mathrm{CDN}$ per pound of body weight loss (Anderson et al. 2009). 
While minimal work exists examining the specific types of interventions that are effective in the workplace, there is general agreement that a combination of multi-component interventions that focus on lifestyle management encompassing stress management, physical activity and nutrition are more effective than programs that focus on a single intervention (e.g. diet or exercise alone) (Schroer et al. 2014). Physical activity increases alertness and can help regulate signals related to appetite and satiety. Increasing opportunities for active breaks may also provide distraction from frequent snacking, especially during night shifts. Where possible, employers should adopt workplace health initiatives (e.g. standing or treadmill desks, walking meetings, promoting active transport to and from work) and reduce individual, environmental and organizational barriers to encourage workers to engage in physical activity and reduce their sitting time.

\section{Nutra-Ergonomic Strategies and Recommendations}

In providing nutra-ergonomic recommendations, it is important to recognize that each worker and worksite is unique. Given this, flexibility in what factors should or need to be considered is required (Figure 1). Generally, employers have a responsibility to provide a safe working environment to both protect the employee and to ensure productivity. Employers consult with various professionals to ensure best practice for fire protection, noise levels, lighting, etc. They take appropriate steps to ensure that employees are well informed and educated in these factors. Nutrition needs to be included in these best practice procedures. Employers need to provide good nutrition education and nutrition opportunities and eliminate the easy access to poor nutritional choices in the same manner that they take responsibility for other elements of the work environment. The below summary lists some nutraergonomic strategies for applicants, workers and employees aimed at facilitating optimal nutrition for physical employment standards, workplace performance as well as long-term worker health. These recommendations are intentionally broad to enable their uptake and subsequent enhancement of the 
health and productivity of workers across active, inactive and shiftwork professions. Future research in the area of nutra-ergonomics is strongly recommended to focus on specific professions, enabling targeted interventions and reviews to provide individualized recommendations for the worker.

- Employers should ensure clean, cooled water is provided and accessible to all employees. Workers should be encouraged to maintain adequate hydration and employers should provide ample time for refreshment breaks, especially in hot and humid work environments and/or during physically-demanding work tasks.

- If caffeine is to be consumed to enhance physical employment standards or worker performance, traditional sources such as coffee and tea are preferable over sugar sweetened 'energy drinks'. Employers are encouraged to create a corporate culture that restricts or discourages consumption of caffeine-containing energy drinks. These strategies may include a restriction of product marketing as well as the removal of such products from vending machines and cafeterias.

- Tyrosine supplementation may have applications in very challenging or prolonged work environments, however there is no current evidence to suggest that tyrosine supplementation is beneficial under less extreme work conditions. The weight of research evidence for a beneficial impact of taurine supplementation is modest at best, with benefits derived from doses of taurine that far exceed that which could be achieved through the diet. Therefore, taurine supplementation is not recommended for the typical worker. 
- Optimal hydration and nutrition practises prior to physical employment standards will likely enhance subsequent performance, with the consumption of stimulants such as caffeine capable of generating a supra-physiological result. However, employers must consider that under these conditions, performance on physical employment standards may not be a true representation of physical performance or subsequent capabilities in the workplace. This will have implications for the employer with regards to the design of physical employment standards, cut-points associated with 'success' on these performance tests and job-specific training when transitioning applicants to incumbent workers.

- Workers need to bring to work or have access to balanced snacks and meals as part of their work routine. These should include a variety of foods that adhere to current food guidelines. The caloric content of meals should be appropriate for the tasks being performed as higher energy jobs may require more calories. Likewise, the employer needs to provide a clean, quiet (limited industry-related or machine noise) and comfortable environment for food consumption. Facilities to heat food, clean-up spills and wash dishes also facilitate healthy eating practices.

- It is recommended that employers regularly review the nutritional profiles and/or the composition of food offered on site. Such a review is not only recommended for employers with formal cafeterias, but also pre-packaged meals and vending machines. Where possible, this nutrition information needs to be made available to employees. A balanced nutritional profile that includes fresh fruit and vegetables, whole grains, legumes, and sources of protein is recommended over high-fat, high-sodium, energy-dense, fast and convenience foods. Likewise, the inclusion of foods high in fiber will help regulate satiety and may also alleviate problems such as constipation and diarrhea which can be common with irregular or shift work. 
- Employers need to monitor and address current food marketing practices within the workplace. Food marketing and promotion is an extremely powerful tool to enhance the sales and consumption of certain products. In particular, the marketing of foods and beverages with less favourable nutritional profiles, including high-sugar, -caffeine, -fat and -salt laden products in the workplace should be monitored, limited and eliminated where possible.

- When possible, providing workers ample time to snack/eat may encourage healthier eating practices and discourage the consumption of single food items or convenience foods. Likewise, allowing workers to eat when hungry rather than on demand encourages appropriate caloric consumption based on physiological cues. This is especially important for the shift worker where cues to eat may be disrupted.

- Improving intake of healthful foods through policy initiatives, vendor collaborations and workplace health initiatives (e.g. price reduction strategies) are encouraged.

- As nutrition and physical activity are closely intertwined, it is important to provide and encourage workers with opportunities for active breaks. Physical activity increases alertness and can help regulate signals related to appetite and satiety. Increasing opportunities for activity may also provide distraction from frequent snacking, especially during night shifts.

- Employers are encouraged to adopt multi-component interventions that focus on lifestyle management encompassing stress management, physical activity (e.g. standing or treadmill desks, walking meetings, promoting active transport to and from work - e.g. provision of secure 
bike storage) and nutrition (examples provided above). Such workplace health initiatives should aim to reduce individual, environmental and organizational barriers to adoption of healthy practices by workers. Such programs have been found to be cost-effective and efficacious.

\section{Conclusions}

Nutra-ergonomics, the interface between workers, their work environment and performance in relation to their nutritional status, plays a vital role in the short- and long-term safety, performance, health and wellbeing of workers. Stimulants and energy or fortified products are commonly used in physical employment standard tests and within the workplace to improve alertness and arousal, however the many and varied side effects of these products mean the benefits are often short lived with potential long-term health consequences. Similar benefits of these 'energy-promoting' products can be achieved by maintaining healthy dietary practices. This is of particular importance for workers with extended work schedules and/or chronic desynchronisation in their work schedule, as is the case in irregular or shift work, due to the greater risk of poor health and the development of various chronic diseases. Awareness and acknowledgement of the roles, responsibilities and implications of both the worker and the employer in nutra-ergonomics is essential to optimize worker health and performance. Whilst workers make the ultimate decisions with respect to the type, timing and volume of food and beverages consumed, it is the responsibility of the employer to create worksite environments that are conducive to healthy nutritional choices. 


\section{Conflicts}

The authors have no conflicts to declare. 


\section{References}

Ainslie, P.N., Campbell, I.T., Frayn, K.N., Humphreys, S.M., MacLaren, D.P., Reilly, T., and Westerterp, K.R. 2002. Energy balance, metabolism, hydration, and performance during strenuous hill walking: the effect of age. J Appl Physiol (1985). 93(2): 714-723.

Alomar, M.Z., Akkam, A., Alashqar, S., and Eldali, A. 2013. Decreased hydration status of emergency department physicians and nurses by the end of their shift. International journal of emergency medicine. 6(1): 27 .

American Dietetic, A., Dietitians of, C., American College of Sports, M., Rodriguez, N.R., Di Marco, N.M., and Langley, S. 2009. American College of Sports Medicine position stand. Nutrition and athletic performance. Med Sci Sports Exerc. 41(3): 709-731.

Anderson, L.M., Quinn, T.A., Glanz, K., Ramirez, G., Kahwati, L.C., Johnson, D.B., Buchanan, L.R., Archer, W.R., Chattopadhyay, S., Kalra, G.P., Katz, D.L., and Task Force on Community Preventive, S. 2009. The effectiveness of worksite nutrition and physical activity interventions for controlling employee overweight and obesity: a systematic review. Am J Prev Med. 37(4): $340-357$.

Antunes, L.C., Levandovski, R., Dantas, G., Caumo, W., and Hidalgo, M.P. 2010. Obesity and shift work: chronobiological aspects. Nutr Res Rev. 23(1): 155-168.

Antypa, N., Van der Does, A.J., Smelt, A.H., and Rogers, R.D. 2009. Omega-3 fatty acids (fish-oil) and depression-related cognition in healthy volunteers. J Psychopharmacol. 23(7): 831-840.

Atkinson, G. and Davenne, D. 2007. Relationships between sleep, physical activity and human health. Physiol Behav. 90(2-3): 229-235. 
Ball, K., McNaughton, S.A., Le, H.N., Gold, L., Ni Mhurchu, C., Abbott, G., Pollard, C., and

Crawford, D. 2015. Influence of price discounts and skill-building strategies on purchase and consumption of healthy food and beverages: outcomes of the Supermarket Healthy Eating for Life randomized controlled trial. Am J Clin Nutr. 101(5): 1055-1064.

Banderet, L.E. and Lieberman, H.R. 1989. Treatment with tyrosine, a neurotransmitter precursor, reduces environmental stress in humans. Brain Res Bull. 22(4): 759-762.

Barbadoro, P., Santarelli, L., Croce, N., Bracci, M., Vincitorio, D., Prospero, E., and Minelli, A. 2013. Rotating shift-work as an independent risk factor for overweight Italian workers: a crosssectional study. PLoS One. 8(5): e63289.

Bauer, I., Crewther, S., Pipingas, A., Sellick, L., and Crewther, D. 2014. Does omega-3 fatty acid supplementation enhance neural efficiency? A review of the literature. Hum Psychopharmacol. 29(1): 8-18.

Beaudoin, M.S., Allen, B., Mazzetti, G., Sullivan, P.J., and Graham, T.E. 2013. Caffeine ingestion impairs insulin sensitivity in a dose-dependent manner in both men and women. Appl Physiol Nutr Metab. 38(2): 140-147.

Berger, L.K., Fendrich, M., Chen, H.Y., Arria, A.M., and Cisler, R.A. 2011. Sociodemographic correlates of energy drink consumption with and without alcohol: results of a community survey. Addict Behav. 36(5): 516-519.

Biggi, N., Consonni, D., Galluzzo, V., Sogliani, M., and Costa, G. 2008. Metabolic syndrome in permanent night workers. Chronobiol Int. 25(2): 443-454. 
Biswas, A., Oh, P.I., Faulkner, G.E., Bajaj, R.R., Silver, M.A., Mitchell, M.S., and Alter, D.A. 2015. Sedentary time and its association with risk for disease incidence, mortality, and hospitalization in adults: a systematic review and meta-analysis. Ann Intern Med. 162(2): 123-132.

Borsheim, E., Tipton, K.D., Wolf, S.E., and Wolfe, R.R. 2002. Essential amino acids and muscle protein recovery from resistance exercise. Am J Physiol Endocrinol Metab. 283(4): E648-657.

Bruce, M., Scott, N., Lader, M., and Marks, V. 1986. The psychopharmacological and electrophysiological effects of single doses of caffeine in healthy-human subjects. Br. J. Clin. Pharmacol. 22(1): 81-87.

Burge, C.M., Carey, M.F., and Payne, W.R. 1993. Rowing performance, fluid balance, and metabolic function following dehydration and rehydration. Med. Sci. Sports Exerc. 25(12): 1358-1364.

Burgueno, A., Gemma, C., Gianotti, T.F., Sookoian, S., and Pirola, C.J. 2010. Increased levels of resistin in rotating shift workers: a potential mediator of cardiovascular risk associated with circadian misalignment. Atherosclerosis. 210(2): 625-629.

Campbell, B., Kreider, R.B., Ziegenfuss, T., La Bounty, P., Roberts, M., Burke, D., Landis, J., Lopez, H., and Antonio, J. 2007. International Society of Sports Nutrition position stand: protein and exercise. J Int Soc Sports Nutr. 4(8.

Campbell, B., Wilborn, C., La Bounty, P., Taylor, L., Nelson, M.T., Greenwood, M., Ziegenfuss, T.N., Lopez, H.L., Hoffman, J.R., Stout, J.R., Schmitz, S., Collins, R., Kalman, D.S., Antonio, J., and Kreider, R.B. 2013. International Society of Sports Nutrition position stand: energy drinks. J Int Soc Sports Nutr. 10(1): 1. 
Chapman, L.S. 2005. Presenteeism and its role in worksite health promotion. Am J Health Promot. 19(4): suppl 1-8.

Coffee Association of Canada (2013). Coffee reigns as the number one beverage of choice for adult Canadians! Toronto, Ontario: Coffee Association of Canada.

Cornelissen, G., Halberg, J., Halberg, F., Sanchez de la Pena, S., Nelson, W., Schwartzkopff, O., Stoynev, A., and Haus, E. 2008. Schedule shifts, cancer and longevity: good, bad or indifferent? Journal of experimental therapeutics \& oncology. 7(4): 263-273.

Dachner, N., Mendelson, R., Sacco, ,J., Tarasuk, V. 2015. An examination of the nutrient content and on-package marketing of novel beverages. Appl. Physiol. Nutr. 40(2): 191-198.

Deijen, J.B., Wientjes, C.J., Vullinghs, H.F., Cloin, P.A., and Langefeld, J.J. 1999. Tyrosine improves cognitive performance and reduces blood pressure in cadets after one week of a combat training course. Brain Res Bull. 48(2): 203-209.

Dietz, W.H. 1998a. Childhood weight affects adult morbidity and mortality. J Nutr. 128(2 Suppl): 411S-414S.

Dietz, W.H. 1998b. Health consequences of obesity in youth: childhood predictors of adult disease. Pediatrics. 101(3 Pt 2): 518-525.

Doherty, M. 1998. The effects of caffeine on the maximal accumulated oxygen deficit and short-term running performance. Int. J. Sport Nutr. 8(2): 95-104.

Ebert, T.R., Martin, D.T., Bullock, N., Mujika, I., Quod, M.J., Farthing, L.A., Burke, L.M., and Withers, R.T. 2007. Influence of hydration status on thermoregulation and cycling hill climbing. Medicine and science in sports and exercise. 39(2): 323-329. 
Eby, G. and Halcomb, W.W. 2006. Elimination of cardiac arrhythmias using oral taurine with 1arginine with case histories: Hypothesis for nitric oxide stabilization of the sinus node. Med Hypotheses. 67(5): 1200-1204.

European Food Safety Authority. 2009. The use of taurine and D-glucurono-gamma-lactone as constituents of the so-called "energy" drinks. The EFSA Journal. 935(1-31.

Fleming, J. and James, L.J. 2014. Repeated familiarisation with hypohydration attenuates the performance decrement caused by hypohydration during treadmill running. Appl Physiol Nutr Metab. 39(2): 124-129.

Fontani, G., Lodi, L., Migliorini, S., and Corradeschi, F. 2009. Effect of omega-3 and policosanol supplementation on attention and reactivity in athletes. J Am Coll Nutr. 28 Suppl(473S-481S.

Fontani, G., Corradeschi, F., Felici, A., Alfatti, F., Migliorini, S., and Lodi, L. 2005. Cognitive and physiological effects of Omega-3 polyunsaturated fatty acid supplementation in healthy subjects. Eur J Clin Invest. 35(11): 691-699.

French, S.A. 2003. Pricing effects on food choices. J Nutr. 133(3): 841S-843S.

Ganio, M.S., Armstrong, L.E., Casa, D.J., McDermott, B.P., Lee, E.C., Yamamoto, L.M., Marzano, S., Lopez, R.M., Jimenez, L., Le Bellego, L., Chevillotte, E., and Lieberman, H.R. 2011. Mild dehydration impairs cognitive performance and mood of men. Br J Nutr. 106(10): 1535-1543.

Gibson, E.L. 2006. Emotional influences on food choice: sensory, physiological and psychological pathways. Physiol Behav. 89(1): 53-61. 
Goetzel, R.Z., Long, S.R., Ozminkowski, R.J., Hawkins, K., Wang, S., and Lynch, W. 2004. Health, absence, disability, and presenteeism cost estimates of certain physical and mental health conditions affecting U.S. employers. J Occup Environ Med. 46(4): 398-412.

Goldstein, E.R., Ziegenfuss, T., Kalman, D., Kreider, R., Campbell, B., Wilborn, C., Taylor, L., Willoughby, D., Stout, J., Graves, B.S., Wildman, R., Ivy, J.L., Spano, M., Smith, A.E., and Antonio, J. 2010. International society of sports nutrition position stand: caffeine and performance. J Int Soc Sports Nutr. 7(1): 5.

Gonzalez-Alonso, J., Calbet, J.A.L., and Nielsen, B. 1998. Muscle blood flow is reduced with dehydration during prolonged exercise in humans. J Physiol-London. 513(3): 895-905.

Graham, T.E. and Spriet, L.L. 1991. Performance and metabolic responses to a high caffeine dose during prolonged exercise. J. Appl. Physiol. 71(6): 2292-2298.

Graham, T.E. and Spriet, L.L. 1995. Metabolic, Catecholamine, and Exercise Performance Responses to Various Doses of Caffeine. J. Appl. Physiol. 78(3): 867-874.

Graham, T.E., Hibbert, E., and Sathasivam, P. 1998. Metabolic and exercise endurance effects of coffee and caffeine ingestion. J. Appl. Physiol. 85(3): 883-889.

Grandner, M.A., Knutson, K.L., Troxel, W., Hale, L., Jean-Louis, G., and Miller, K.E. 2014. Implications of sleep and energy drink use for health disparities. Nutr Rev. 72 Suppl 1(14-22.

Hamazaki, T., Sawazaki, S., Itomura, M., Asaoka, E., Nagao, Y., Nishimura, N., Yazawa, K., Kuwamori, T., and Kobayashi, M. 1996. The effect of docosahexaenoic acid on aggression in young adults. A placebo-controlled double-blind study. J Clin Invest. 97(4): 1129-1133. 
Harnack, L., Stang, J., and Story, M. 1999. Soft drink consumption among US children and adolescents: nutritional consequences. J Am Diet Assoc. 99(4): 436-441.

Hasenfratz, M. and Battig, K. 1994. Acute dose-effect relationships of caffeine and mental performance, EEG, cardiovascular and subjective parameters. Psychopharmacology. 114(2): $281-287$.

Haskell, C.F., Kennedy, D.O., Wesnes, K.A., and Scholey, A.B. 2005. Cognitive and mood improvements of caffeine in habitual consumers and habitual non-consumers of caffeine. Psychopharmacology (Berl.). 179(4): 813-825.

Health Canada (2010). Dietary Reference Intakes Tables: Health Canada.

Hespel, P., Maughan, R.J., and Greenhaff, P.L. 2006. Dietary supplements for football. J. Sports Sci. 24(7): 749-761.

Hill, J.O., Wyatt, H.R., and Peters, J.C. 2012. Energy balance and obesity. Circulation. 126(1): 126132.

Hunt, A.P., Parker, A.W., and Stewart, I.B. 2014. Heat strain and hydration status of surface mine blast crew workers. J Occup Environ Med. 56(4): 409-414.

Jackson, D.A., Cotter, B.V., Merchant, R.C., Babu, K.M., Baird, J.R., Nirenberg, T., and Linakis, J.G. 2013. Behavioral and physiologic adverse effects in adolescent and young adult emergency department patients reporting use of energy drinks and caffeine. Clin Toxicol (Phila). 51(7): $557-565$. 
Jackson, P.A., Deary, M.E., Reay, J.L., Scholey, A.B., and Kennedy, D.O. 2012. No effect of 12 weeks' supplementation with $1 \mathrm{~g}$ DHA-rich or EPA-rich fish oil on cognitive function or mood in healthy young adults aged 18-35 years. Br J Nutr. 107(8): 1232-1243.

Janssen, I. 2013. The public health burden of obesity in Canada. Can J Diabetes. 37(2): 90-96.

Jensen, J.D. 2011. Can worksite nutritional interventions improve productivity and firm profitability? A literature review. Perspect Public Health. 131(4): 184-192.

Kim, M.J., Son, K.H., Park, H.Y., Choi, D.J., Yoon, C.H., Lee, H.Y., Cho, E.Y., and Cho, M.C. 2013. Association between shift work and obesity among female nurses: Korean Nurses' Survey. BMC Public Health. 13(1204.

Knutson, A., Andersson, H., and Berglund, U. 1990. Serum lipoproteins in day and shift workers: a prospective study. British journal of industrial medicine. 47(2): 132-134.

Knutson, K.L. and Van Cauter, E. 2008. Associations between sleep loss and increased risk of obesity and diabetes. Ann N Y Acad Sci. 1129(287-304.

Knutsson, A. and Boggild, H. 2000. Shiftwork and cardiovascular disease: review of disease mechanisms. Reviews on environmental health. 15(4): 359-372.

Konturek, P.C., Brzozowski, T., and Konturek, S.J. 2011. Gut clock: implication of circadian rhythms in the gastrointestinal tract. Journal of physiology and pharmacology : an official journal of the Polish Physiological Society. 62(2): 139-150.

Leone, V., Gibbons, S.M., Martinez, K., Hutchison, A.L., Huang, E.Y., Cham, C.M., Pierre, J.F., Heneghan, A.F., Nadimpalli, A., Hubert, N., Zale, E., Wang, Y., Huang, Y., Theriault, B., Dinner, A.R., Musch, M.W., Kudsk, K.A., Prendergast, B.J., Gilbert, J.A., and Chang, E.B. 
2015. Effects of diurnal variation of gut microbes and high-fat feeding on host circadian clock function and metabolism. Cell host \& microbe. 17(5): 681-689.

Linseisen, J. and Wolfram, G. 1994. [Nutrient intake in permanent night shift workers]. Zeitschrift fur Ernahrungswissenschaft. 33(4): 299-309.

Lloret-Linares, C., Lafuente-Lafuente, C., Chassany, O., Green, A., Delcey, V., Mouly, S., and Bergmann, J.F. 2012. Does a single cup of coffee at dinner alter the sleep? A controlled crossover randomised trial in real-life conditions. Nutrition \& Dietetics. 69(250-255.

Lopez, R.M., Casa, D.J., Jensen, K.A., DeMartini, J.K., Pagnotta, K.D., Ruiz, R.C., Roti, M.W., Stearns, R.L., Armstrong, L.E., and Maresh, C.M. 2011. Examining the influence of hydration status on physiological responses and running speed during trail running in the heat with controlled exercise intensity. Journal of strength and conditioning research / National Strength \& Conditioning Association. 25(11): 2944-2954.

Lowden, A., Moreno, C., Holmback, U., Lennernas, M., and Tucker, P. 2010. Eating and shift work effects on habits, metabolism and performance. Scandinavian journal of work, environment \& health. 36(2): 150-162.

Ludwig, I.A., Clifford, M.N., Lean, M.E., Ashihara, H., and Crozier, A. 2014. Coffee: biochemistry and potential impact on health. Food Funct. 5(8): 1695-1717.

Mahoney, C.R., Castellani, J., Kramer, F.M., Young, A., and Lieberman, H.R. 2007. Tyrosine supplementation mitigates working memory decrements during cold exposure. Physiol Behav. 92(4): 575-582. 
Manenschijn, L., van Kruysbergen, R.G., de Jong, F.H., Koper, J.W., and van Rossum, E.F. 2011. Shift work at young age is associated with elevated long-term cortisol levels and body mass index. J Clin Endocrinol Metab. 96(11): E1862-1865.

Masento, N.A., Golightly, M., Field, D.T., Butler, L.T., and van Reekum, C.M. 2014. Effects of hydration status on cognitive performance and mood. Br J Nutr. 111(10): 1841-1852.

Maughan, R.J. 2003. Impact of mild dehydration on wellness and on exercise performance. Eur. J. Clin. Nutr. 57(Suppl 2): S19-23.

Maughan, R.J., Bethell, L.R., and Leiper, J.B. 1996. Effects of ingested fluids on exercise capacity and on cardiovascular and metabolic responses to prolonged exercise in man. Experimental physiology. 81(5): 847-859.

Maughan, R.J., Shirreffs, S.M., and Watson, P. 2007. Exercise, heat, hydration and the brain. J Am Coll Nutr. 26(5 Suppl): 604S-612S.

McConell, G.K., Burge, C.M., Skinner, S.L., and Hargreaves, M. 1997. Influence of ingested fluid volume on physiological responses during prolonged exercise. Acta Physiol Scand. 160(2): $149-156$.

Mentes, J. 2006. Oral hydration in older adults: greater awareness is needed in preventing, recognizing, and treating dehydration. The American journal of nursing. 106(6): 40-49; quiz 50.

Miescher, E. and Fortney, S.M. 1989. Responses to dehydration and rehydration during heat exposure in young and older men. Am J Physiol. 257(5 Pt 2): R1050-1056.

Miller, K.E. 2008. Wired: energy drinks, jock identity, masculine norms, and risk taking. Journal of American college health : J of ACH. 56(5): 481-489. 
Moriguchi, T. and Salem, N., Jr. 2003. Recovery of brain docosahexaenoate leads to recovery of spatial task performance. J Neurochem. 87(2): 297-309.

Mozaffari, M.S., Patel, C., Abdelsayed, R., and Schaffer, S.W. 2006. Accelerated NaCl-induced hypertension in taurine-deficient rat: role of renal function. Kidney Int. 70(2): 329-337.

Must, A. and Strauss, R.S. 1999. Risks and consequences of childhood and adolescent obesity. Int. J. Obes. Relat. Metab. Disord. 23 (Suppl 2): S2-11.

Must, A. and Lipman, R.D. 1999. Childhood energy intake and cancer mortality in adulthood. Nutr Rev. 57(1): 21-24.

Neri, D.F., Wiegmann, D., Stanny, R.R., Shappell, S.A., McCardie, A., and McKay, D.L. 1995. The effects of tyrosine on cognitive performance during extended wakefulness. Aviation, space, and environmental medicine. 66(4): 313-319.

Ni Mhurchu, C., Aston, L.M., and Jebb, S.A. 2010. Effects of worksite health promotion interventions on employee diets: a systematic review. BMC Public Health. 10(62.

Noordzij, M., Uiterwaal, C., Arends, L.R., Kok, F.J., Grobbee, D.E., and Geleijnse, J.M. 2005. Blood pressure response to chronic intake of coffee and caffeine: a meta-analysis of randomized controlled trials. J. Hypertens. 23(5): 921-928.

Parkes, K.R. 2002. Shift work and age as interactive predictors of body mass index among offshore workers. Scandinavian journal of work, environment \& health. 28(1): 64-71.

Parnell, J.A. and Reimer, R.A. 2012. Prebiotic fiber modulation of the gut microbiota improves risk factors for obesity and the metabolic syndrome. Gut microbes. 3(1): 29-34. 
Pichainarong, N., Chaveepojnkamjorn, W., Khobjit, P., Veerachai, V., and Sujirarat, D. 2004. Energy drinks consumption in male construction workers, Chonburi province. J Med Assoc Thai. 87(12): 1454-1458.

Polkinghorne, B.G., Gopaldasani, V., Furber, S., Davies, B., and Flood, V.M. 2013. Hydration status of underground miners in a temperate Australian region. BMC Public Health. 13(426.

Preedy, V.R. (2015). Coffee in Health and Disease Prevention. London, UK: Academic Press, Elsevier.

Public Health Agency of Canada (2011). Obesity in Canada: A joint report from the Public Health Agency of Canada and the Canadian Institute for Health Information. Ottawa, Canada: Public Health Agency of Canada.

Reeder, B., Senthilselvan, A., Després, J., Angel, A., Liu, L., and Wang, H.e.a. 1997. The association of cardiovascular disease risk factors with abdominal obesity in Canada. CMAJ. 157(Suppl 1): S39-S45.

ReportsnReports (2013). U.S. Energy Drinks and Shots Market Analysis and Forecast to 2017 in New Research Report

Sawka, M.N., Burke, L.M., Eichner, E.R., Maughan, R.J., Montain, S.J., and Stachenfeld, N.S. 2007. American College of Sports Medicine position stand. Exercise and fluid replacement. Med Sci Sports Exerc. 39(2): 377-390.

Schaffer, S. 2014. Other Compounds Impacting Caffeine Effects. In Planning Committee for a Workshop on Potential Health Hazards Associated with Consumption of Caffeine in Food and Dietary Supplements; Food and Nutrition Board; Board on Health Sciences Policy; Institute of 
Medicine. Caffeine in Food and Dietary Supplements: Examining Safety: Workshop Summary. Edited by National Academies Press (US), Washington (DC). pp. 129-144.

Schroer, S., Haupt, J., and Pieper, C. 2014. Evidence-based lifestyle interventions in the workplace - an overview. Occupational medicine. 64(1): 8-12.

Shearer, J. 2014. Caffeine containing energy drinks: methodological considerations and impact on the gastrointestinal system, liver and metabolic health. Nutr. Rev. 72(Suppl 1): 137-145.

Shearer, J. and Graham, T.E. 2014. Caffeine and Caffeinated Energy Drink Consumption: A Systematic Review of Performance and Metabolic Consequences on Glucose Disposal. Nutr. Rev. 72 (1): 121-136.

Shearer, J. and Elliott, C. 2015. Manufacturer-driven discretionary nutritional fortification of "novel beverages". Appl Physiol Nutr Metab. 40(2): iii-iv.

Shurtleff, D., Thomas, J.R., Schrot, J., Kowalski, K., and Harford, R. 1994. Tyrosine reverses a coldinduced working memory deficit in humans. Pharmacol Biochem Behav. 47(4): 935-941.

Sinclair, A.J., Begg, D., Mathai, M., and Weisinger, R.S. 2007. Omega 3 fatty acids and the brain: review of studies in depression. Asia Pac J Clin Nutr. 16 Suppl 1(391-397.

Smith, A. 2002. Effects of caffeine on human behavior. Food Chem Toxicol. 40(9): 1243-1255.

Sookoian, S., Gemma, C., Fernandez Gianotti, T., Burgueno, A., Alvarez, A., Gonzalez, C.D., and Pirola, C.J. 2007. Effects of rotating shift work on biomarkers of metabolic syndrome and inflammation. J Intern Med. 261(3): 285-292. 
Spriet, L.L. and Gibala, M.J. 2004. Nutritional strategies to influence adaptations to training. J. Sports Sci. 22(1): 127-141.

Spriet, L.L., Maclean, D.A., Dyck, D.J., Hultman, E., Cederblad, G., and Graham, T.E. 1992. Caffeine Ingestion and Muscle Metabolism During Prolonged Exercise in Humans. Am. J. Physiol. 262(6): E891-E898.

Stephens, M.B., Attipoe, S., Jones, D., Ledford, C.J., and Deuster, P.A. 2014. Energy drink and energy shot use in the military. Nutr. Rev. 72 (Suppl 1): 72-77.

Stewart, W.F., Ricci, J.A., Chee, E., Morganstein, D., and Lipton, R. 2003. Lost productive time and cost due to common pain conditions in the US workforce. JAMA. 290(18): 2443-2454.

Szinnai, G., Schachinger, H., Arnaud, M.J., Linder, L., and Keller, U. 2005. Effect of water deprivation on cognitive-motor performance in healthy men and women. Am J Physiol Regul Integr Comp Physiol. 289(1): R275-280.

Tada, Y., Kawano, Y., Maeda, I., Yoshizaki, T., Sunami, A., Yokoyama, Y., Matsumoto, H., Hida, A., Komatsu, T., and Togo, F. 2014. Association of body mass index with lifestyle and rotating shift work in Japanese female nurses. Obesity (Silver Spring). 22(12): 2489-2493.

Tassoni, D., Kaur, G., Weisinger, R.S., and Sinclair, A.J. 2008. The role of eicosanoids in the brain. Asia Pac J Clin Nutr. 17 Suppl 1(220-228.

The Economist (2013). Buzz kill - Safety concerns threaten the market for caffeinated food and drink

Thomas, J.R., Lockwood, P.A., Singh, A., and Deuster, P.A. 1999. Tyrosine improves working memory in a multitasking environment. Pharmacol Biochem Behav. 64(3): 495-500. 
Tremblay, M.S. and Willms, J.D. 2003. Is the Canadian childhood obesity epidemic related to physical inactivity? Int J Obes Relat Metab Disord. 27(9): 1100-1105.

Tumilty, L., Davison, G., Beckmann, M., and Thatcher, R. 2011. Oral tyrosine supplementation improves exercise capacity in the heat. Eur J Appl Physiol. 111(12): 2941-2950.

Tumilty, L., Davison, G., Beckmann, M., and Thatcher, R. 2014. Failure of oral tyrosine supplementation to improve exercise performance in the heat. Med Sci Sports Exerc. 46(7): $1417-1425$.

Twells, L.K., Gregory, D.M., Reddigan, J., and Midodzi, W.K. 2014. Current and predicted prevalence of obesity in Canada: a trend analysis. CMAJ open. 2(1): E18-26.

Ulhoa, M.A., Marqueze, E.C., Kantermann, T., Skene, D., and Moreno, C. 2011. When does stress end? Evidence of a prolonged stress reaction in shiftworking truck drivers. Chronobiol Int. 28(9): 810-818.

van Duijvenbode, D.C., Hoozemans, M.J., van Poppel, M.N., and Proper, K.I. 2009. The relationship between overweight and obesity, and sick leave: a systematic review. Int J Obes (Lond). 33(8): 807-816.

Waern, R.V., Cumming, R.G., Blyth, F., Naganathan, V., Allman-Farinelli, M., Le Couteur, D., Simpson, S.J., Kendig, H., and Hirani, V. 2015. Adequacy of nutritional intake among older men living in Sydney, Australia: findings from the Concord Health and Ageing in Men Project (CHAMP). Br J Nutr. 114(5): 812-821.

Walpole, S.C., Prieto-Merino, D., Edwards, P., Cleland, J., Stevens, G., and Roberts, I. 2012. The weight of nations: an estimation of adult human biomass. BMC Public Health. 12(439. 
Wang, X.S., Armstrong, M.E., Cairns, B.J., Key, T.J., and Travis, R.C. 2011. Shift work and chronic disease: the epidemiological evidence. Occupational medicine. 61(2): 78-89.

Waterlander, W.E., de Boer, M.R., Schuit, A.J., Seidell, J.C., and Steenhuis, I.H. 2013. Price discounts significantly enhance fruit and vegetable purchases when combined with nutrition education: a randomized controlled supermarket trial. Am J Clin Nutr. 97(4): 886-895.

Watson, P., Enever, S., Page, A., Stockwell, J., and Maughan, R.J. 2012. Tyrosine supplementation does not influence the capacity to perform prolonged exercise in a warm environment. Int $\mathbf{J}$ Sport Nutr Exerc Metab. 22(5): 363-373.

Wellard, L., Hughes, C., Tsang, Y.W., Watson, W., and Chapman, K. 2014. Investigating fruit and vegetable claims on Australian food packages. Public Health Nutr. 14(1-7.

World Health Organization Nutrition: Population nutrient intake goals for preventing diet-related chronic diseases.

Wu, G. 2016. Dietary protein intake and human health. Food \& function.

Zhao, I., Bogossian, F., Song, S., and Turner, C. 2011. The association between shift work and unhealthy weight: a cross-sectional analysis from the Nurses and Midwives' e-cohort Study. J Occup Environ Med. 53(2): 153-158.

Zwart, S.R., Davis-Street, J.E., Paddon-Jones, D., Ferrando, A.A., Wolfe, R.R., and Smith, S.M. 2005. Amino acid supplementation alters bone metabolism during simulated weightlessness. J Appl Physiol (1985). 99(1): 134-140. 


\section{Figure Legend}

Figure 1. Nutra-Ergonomic model of information processing. This schematic considers the increasingly complex food environment as it relates to the workplace and that each worksite varies in terms of its demands on workers and their nutritional needs. Nutritional information and considerations enter the funnel. Factors are filtered depending on the work task, work environment, nature of employee, etc. For example, the filter is selective allowing water, healthy foods, low to moderate caffeine to pass to the employee, while the filter removes excessive calories, high caffeine, certain supplements, single item meals, etc. Figure is original with exception of the Funnel from Colourbox.com under a University of Calgary license. 
Factors [Influenced by Food Environment, Worker Education, Hydration/Caloric Needs, Food Availability, Preference, Marketing, Timing, Irregular, Shift-Work, etc.]

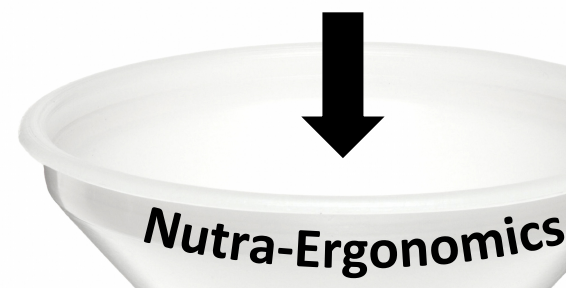

Rejected Factors

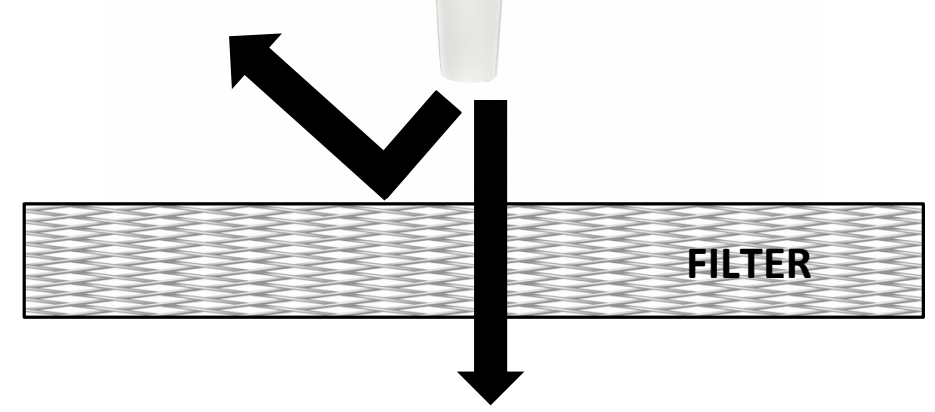

Accepted Factors

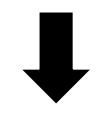

Worker Retention

Long-term Health and Wellbeing

Improved Productivity

Health and Safety 